\title{
Determinants of Ruptured Cerebral Aneurysm and the Presenting Symptoms among Patients with SAH Admitted at a Tertiary Care Center in North India
}

\author{
Mahendra Kumar ${ }^{1}$, Sukhpal Kaur ${ }^{2}$, Ashish Aggarwal $^{3}$, Pravin Salunke ${ }^{4}$, Monaliza Mittal ${ }^{5}$
}

\begin{abstract}
Introduction: Aneurysmal subarachnoid hemorrhage $(\mathrm{SAH})$ is a serious disease with high rates of mortality and morbidity. The current study is carried out to assess the risk factors and clinical profile of the patients with aneurysmal SAH presenting to a tertiary care center in India.

Materials and methods: A single-center cross-sectional study was carried out on 65 cerebral aneurysm patients with an aneurysmal SAH. The sociodemographic details, comorbidities, risk factors, and the presenting symptoms experienced by the patients at the time of rupture of aneurysm were recorded by using a pre-validated questionnaire.

Results: The age of the participants ranged between 41 and 55 years and the majority were female. Maximum had experienced severe headache followed by vomiting and neck stiffness before rupturing of the aneurysm. Age above 45 years followed by hypertension, female gender, and smoking were identified as major risk factors among the study subjects.

Conclusion: Advanced age, smoking, and female gender are found main risk factors with severe headache, vomiting, and neck rigidity as main symptoms. Risk factors and symptoms are important to know for future research and preparing treatment modules.

Keywords: Cerebral aneurysm, Risk factors, Ruptured symptoms.

Pondicherry Journal of Nursing (2021): 10.5005/jp-journals-10084-12172
\end{abstract}

\section{INTRODUCTION}

A cerebral aneurysm is one of the major cerebrovascular diseases causing detrimental effects on individuals' health and performance due to rupturing and creating subarachnoid hemorrhage (SAH). ${ }^{1}$

A brain aneurysm is an abnormal focal dilation of a blood vessel wall in the brain resulting from the weakening of the inner muscle layer of the blood vessel wall.

Aneurysm rupture with resultant $\mathrm{SAH}$ is the most feared consequence of unruptured intracranial aneurysms. This wall gets weakened by injury or any disease. ${ }^{1,2}$

Aneurysm rupture is one of the most intricate complications of cerebral aneurysms and about $80 \%$ of non-traumatic SAHs are related to rupture of cerebral aneurysms where the mortality rate is as high as $45 \% .^{2-4}$ Prompt detection and timely treatment are censorious for good recovery and outcomes in patients with nontraumatic $\mathrm{SAH} .^{4}$

Usually, aneurysms remain silent till rupture and then present with acute and varity of symptoms including sudden headache and neck rigidity. Focal neurological deficits are likely due to an increase in mass effect, or any event of cerebral ischemia distal to the site of the aneurysm. ${ }^{5}$

Patients who present to triage with symptoms, such as, acute loss of consciousness, severe headache which is often accompanied by vomiting, and neck rigidness indicate the presence of aneurysmal $\mathrm{SAH} .{ }^{5}$ In $30 \%$ of ruptured cerebral aneurysm patients, headache is usually lateralized to the side of the aneurysm. ${ }^{6,7}$

Subarachnoid hemorrhages most often with cerebral aneurysms are silent and present with a bleed in the brain. ${ }^{8} \mathrm{~A}$ study conducted in Japan reported $>90 \%$ of cerebral aneurysm cases detected incidentally raise the need for an institutional systemic
${ }^{1}$ Department of Neurology, Postgraduate Institute of Medical Education and Research, Chandigarh, India

2,5 Department of Nursing, Postgraduate Institute of Medical Education and Research, Chandigarh, India

${ }^{3}$ Department of Neurosurgery, Postgraduate Institute of Medical Education and Research, Chandigarh, India

${ }^{4}$ National Institute of Nursing Education, PGIMER, Chandigarh, India

Corresponding Author: Mahendra Kumar, Department of Neurology, Postgraduate Institute of Medical Education and Research, Chandigarh, India, Phone: +91 9465223015, e-mail: kumarmahen9@gmail.com

How to cite this article: Kumar M, Kaur S, Aggarwal A, Salunke P, Mittal $M$. Determinants of Ruptured Cerebral Aneurysm and the Presenting Symptoms among Patients with SAH Admitted at a Tertiary Care Center in North India. Pon J Nurs 2021;14(1):2-7.

Source of support: Nil

Conflict of interest: None

approach of preventive methods, such as, mass screening to detect unruptured aneurysms. ${ }^{9}$

A raised incidence of the ruptured cerebral aneurysm has been found in patients with certain predisposing factors, such as, advanced age, hypertension, smoking, alcohol abuse, and atherosclerosis. ${ }^{2,10}$ Cigarette smoking and hypertension are among the leading influencing factors of non-traumatic SAH. ${ }^{11,12}$

The peak incidence of cerebral aneurysm rupture is among the age group between 40 and 60 years, with 53 years as the mean age. ${ }^{11}$ A meta-analysis on aneurysmal SAH depicts that this disproportionally affects more to women likely causes being stress, reproductive factors, and some other genetic variations expanding the risk in women. ${ }^{13}$ 
Further aggravating factors include alcohol habits, personal or family history of aneurysm, hemorrhagic stroke, and cerebrovascular disease. ${ }^{11,14}$ Diabetic mellitus is another well-known predisposing factor for cerebral infarction. ${ }^{15-18}$ World Federation of Neurosurgical Societies (WFNS), Hunt and Hess, and Fisher grade scales are worldwide being used to observe the severity of ruptured aneurysm and give a prediction of treatment outcome. ${ }^{19}$

\section{Aim of the Study}

The present study aimed to predict the determinants of ruptured cerebral aneurysms among patients presenting at a tertiary care hospital in North India.

\section{Materials and Methods}

A single-center cross-sectional study was carried out at a tertiary care center in Chandigarh, India.

Sixty-five ruptured cerebral aneurysm patients presented in the neurosurgery unit of the institute from June 2017 to September 2017 were enrolled in the study. For all the ruptured aneurysm, CT was used for initial diagnosis and treatment decision-making. The identification data of patients with ruptured cerebral aneurysms treated/presented at the mentioned center were extracted from the list of admission records. The required information was obtained from the next kin of the patients, an archive of hospital records, and documented in the study questionnaire. Ethical permission was obtained from the Institutional Ethics Committee. The anonymity of the information of the patient was ensured. Written informed consent was taken from all the patients or their next of kin, as applicable.

\section{Inclusion Criteria}

All ruptured cerebral aneurysm patients presented to the given tertiary care center during the study period.

\section{Exclusion Criteria}

Subarachnoid hemorrhage due to any other cause (trauma, intracranial arteriovenous malformations, hypertension, and coagulopathy).

\section{Questionnaire}

A pre-validated questionnaire was used to collect the information from study subjects including demographic details, such as, the age of patients, gender, and occupation. The clinical profile consisted of symptoms experienced by the patients at the time of aneurysm rupture, risk factors, such as, comorbidities, and severity grading of aneurismal subarachnoid hemorrhage (aSAH) as per WFNS, $\mathrm{H}$ and $\mathrm{H}$, and Fisher grade scales. The clinical characteristics analyzed as a known case of hypertension (we kept diagnosed hypertension as time after time systolic blood pressure (SBP) $>140 \mathrm{~mm} \mathrm{Hg}$ or diastolic blood pressure over $90 \mathrm{~mm} \mathrm{Hg}$, or on blood pressure control medication), diabetics, smoking habits (ex-smokers or history of smoking over 10 years, and continued smokers), and habit of alcohol intake.

\section{Results}

Table 1 depicts the demographic and clinical characteristics of the patients. The mean \pm SD age of the patients was $49.82 \pm 11.61$ years. The majority of the patients were female (56.9\%). $41.5 \%$ of study participants were educated up to senior secondary whereas
Table 1: Sociodemographic determinants of study participants $(N=65)$

\begin{tabular}{|c|c|}
\hline Variable & $n(\%)$ \\
\hline \multicolumn{2}{|l|}{ Age (years) } \\
\hline $18-29$ & $06(9.3)$ \\
\hline $30-44$ & $10(15.4)$ \\
\hline 45 years and above & $49(75.3)$ \\
\hline \multicolumn{2}{|c|}{ Age: mean \pm SD: $49.82 \pm 11.61$} \\
\hline \multicolumn{2}{|l|}{ Range: $18-64$ years } \\
\hline \multicolumn{2}{|l|}{ Gender } \\
\hline Male & $28(43.1)$ \\
\hline Female & $37(56.9)$ \\
\hline \multicolumn{2}{|l|}{ Educational status } \\
\hline Just literate & $20(30.8)$ \\
\hline Up to middle class & $18(27.7)$ \\
\hline Senior secondary and above & $27(41.5)$ \\
\hline \multicolumn{2}{|l|}{ Area of living } \\
\hline Rural & $55(84.6)$ \\
\hline Urban & $10(15.4)$ \\
\hline \multicolumn{2}{|l|}{ Religion } \\
\hline Hindu & $51(78.5)$ \\
\hline Sikh & $8(12.3)$ \\
\hline Others (Muslim, Christian) & $06(9.2)$ \\
\hline \multicolumn{2}{|l|}{ Type of family } \\
\hline Nuclear & $11(16.9)$ \\
\hline Joint & $54(83.1)$ \\
\hline \multicolumn{2}{|l|}{ Occupation } \\
\hline Not working/homemaker & $40(61.5)$ \\
\hline Skilled/unskilled worker & $06(9.2)$ \\
\hline Govt. employee & $09(13.8)$ \\
\hline Agriculture & $10(15.4)$ \\
\hline
\end{tabular}

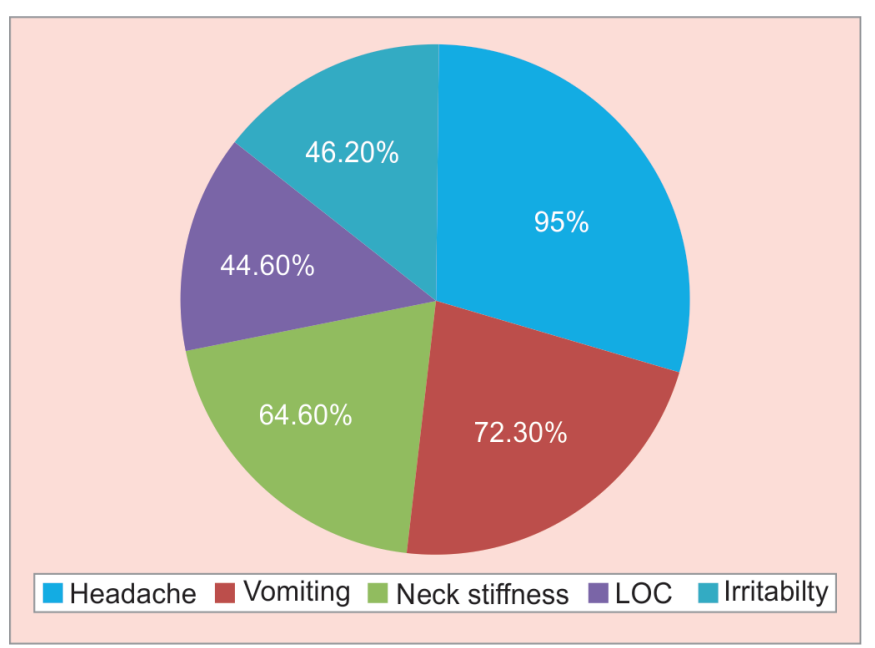

Fig. 1: Symptoms of ruptured cerebral aneurysm $(N=65)$

$30.8 \%$ were just literate. Maximum (84.6\%) of participants were from rural areas and were Hindu (78.5\%) by religion. $61.5 \%$ of the patients were either not working or homemakers as more than half of the patients were female.

Figure 1 shows that $95.4 \%$ of the patients experienced a headache after the rupture of aneurysm followed by vomiting (72.3\%). Neck stiffness was reported by 64.6 and $46.4 \%$ of 
participants reported irritability. Loss of consciousness was reported among $44.6 \%$ of patients with a mean \pm SD duration of $4.82 \pm 6.92$.

Hypertension was reported by $64.6 \%$ with the mean \pm SD duration of $4.35 \pm 3.79$ years of the disease. History of diabetes mellitus was reported by $9.2 \%$ with the mean \pm SD duration of $7.67 \pm 2.73$ years. Treatment adherence was better in the case of diabetes mellitus (83\%) as compared to hypertension. All the patients suffering from seizures and chronic obstructive pulmonary disease (COPD) had good adherence to treatment (Table 2).

Advanced age, above 45 years was the major risk factor reported from study results as $75.3 \%$ of patients were above 45 years of age and the second main risk factor was the female gender (56.9\%). The habit of smoking was reported by $29.2 \%$ with the mean \pm SD duration of $3.20 \pm 6.16$ years. $21.5 \%$ had a history of alcohol consumption (Figs 2 and 3 ).

Table 3 depicts the severity of ruptured cerebral aneurysm as assessed by three scales. As per Hunt and Huss scale, $58.7 \%$ were in grade I with the mean \pm SD score of $2.29 \pm 0.669$. World Federation of Neurosurgical Societies grade I was $38.5 \%$ with a mean \pm SD score of $1.89 \pm 0.868$ as leading. Equally, $41.7 \%$ of patients had Fisher grade I, grade III SAH on CT scan, and mean \pm SD was 3.20 \pm 0.887 . A total of 56.92 patients were having an aneurysm at the anterior cerebral artery/internal carotid artery (ACA/ICA) location.

Out of 65 patients, 36 (55.4\%) were conscious at presentation. The mean duration \pm SD of loss of consciousness (LOC) was $4.82 \pm$ 6.92 , whereas $55.4 \%$ did not report LOC. $18.4 \%$ of study participants had 6 to 10 minutes duration of LOC. The majority of the aneurysm (56.9\%) were located at ICA/ACA and the maximum (87.7\%) were secular aneurysms (Table 4).

$78.5 \%$ of subjects reached the tertiary healthcare centers on the same day and $10.7 \%$ reached within 5-7 days with a mean \pm SD of $2.74 \pm 1.98$.

Table 2: Risk factors (comorbidities) associated with ruptured cerebral aneurysm $(N=6)$

\begin{tabular}{llll}
\hline Variables & $N(\%)$ & $\begin{array}{l}\text { Duration comorbidities } \\
(\text { Mean } \pm \text { SD) }\end{array}$ & $\begin{array}{l}\text { Treatment } \\
\text { adherence }\end{array}$ \\
\hline Hypertension & $42(64.6)$ & $4.35 \pm 3.79$ & $24(57.14 \%)$ \\
Diabetic mellitus & $06(9.2)$ & $7.67 \pm 2.73$ & $05(83 \%)$ \\
Seizure & $02(3.1)$ & $2.20 \pm 3.19$ & $02(100 \%)$ \\
COPD & $02(3.1)$ & $12.50 \pm 3.53$ & $02(100 \%)$ \\
\hline
\end{tabular}

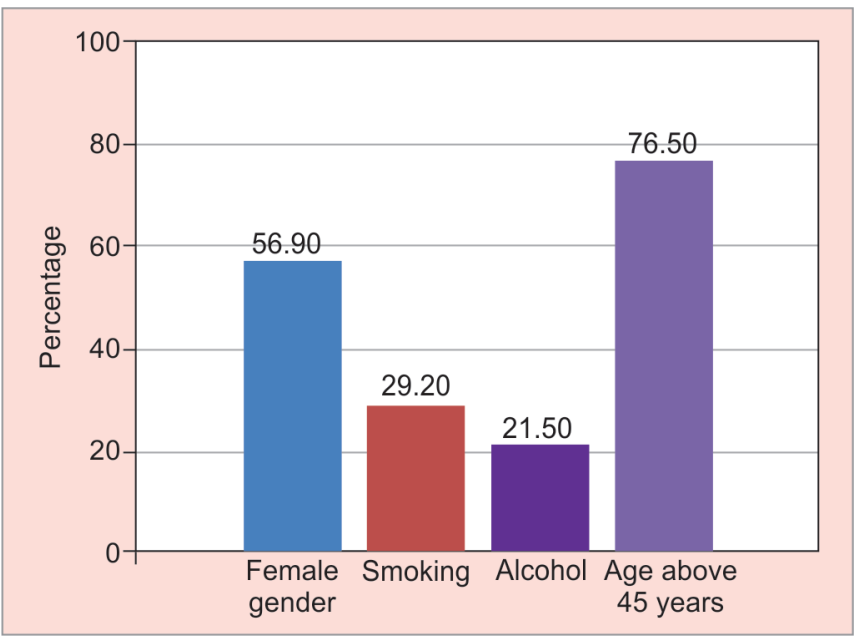

Fig. 2: Risk factors of ruptured cerebral aneurysm $(N=65)$

\section{Discussion}

Subarachnoid hemorrhage is among the most destructive neurological diseases. This disease not only impacts the consequential effect on morbidity and mortality but also conveys awful social and financial consequences. ${ }^{3}$

The present study was carried out at a well-known over 2,000 beds capacity tertiary health care center in Chandigarh, India. It is also known as a center for excellence with mass volume in neurosurgical cases. Aneurysmal $\mathrm{SAH}$ is a catastrophic acute neurological disease that impacts over 30,000 population annually in the USA. ${ }^{4}$

The intrinsic complexities of the treatment have a high impact on advancements in investigation facilities and treatment modalities mean that these patients can be more effectively treated at tertiary care centers. According to the results obtained from our study and other studies, age is a factor affecting the incidence of an aneurysm. About two-thirds (75.3\%) of study participants were above the age of 45 years with an average age of $49.82 \pm 11.61$

Table 3: Clinical severity grading of ruptured cerebral aneurysm $(N=65)$

\begin{tabular}{ll}
\hline Clinical grading & $n(\%)$ \\
\hline Hunt and Huss scale & \\
Grade I & $05(7.7)$ \\
Grade II & $38(58.7)$ \\
Grade III & $20(30.8)$ \\
Grade IV & $02(3.1)$ \\
Mean \pm SD $2.29 \pm 0.669$ & \\
WFNS grade (at presentation) & \\
Grade I & $25(38.5)$ \\
Grade II & $24(36.9)$ \\
Grade III & $15(23.1)$ \\
Grade IV & $01(1.5)$ \\
Mean \pm SD $1.89 \pm 0.868$ & \\
Fisher: CT grade & \\
Grade I & \\
Grade II & $27(41.7)$ \\
Grade III & $07(10.8)$ \\
Grade IV & $27(41.7)$ \\
Mean \pm SD $3.20 \pm 0.887$ & $04(6.1)$ \\
\hline
\end{tabular}

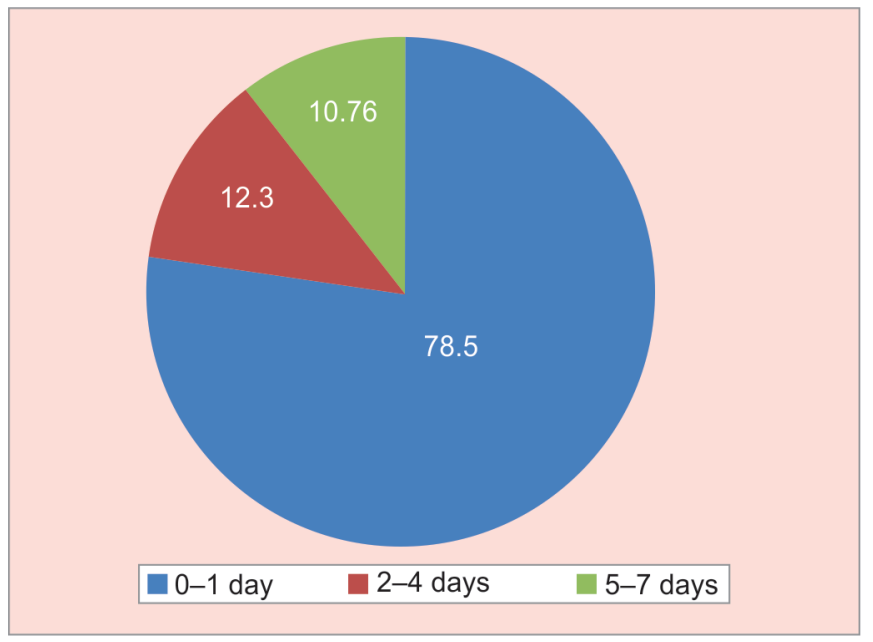

Fig. 3: Time duration to reach tertiary health care $(N=65)$ 


\begin{tabular}{|c|c|c|}
\hline & Variable & $N(\%)$ \\
\hline \multirow[t]{6}{*}{1} & Duration of LOC & \\
\hline & No LOC & $36(55.4)$ \\
\hline & $1-5$ minutes & $10(15.3)$ \\
\hline & $6-10$ minutes & $12(18.4)$ \\
\hline & 11 minutes or above & $07(10.7)$ \\
\hline & Mean \pm SD $4.82 \pm 6.92$ & \\
\hline \multirow[t]{5}{*}{2} & Location of aneurysm & \\
\hline & ICA/ACA & $37(56.92)$ \\
\hline & A.com. & $14(21.53)$ \\
\hline & MCA & $09(13.8)$ \\
\hline & Posterior circulation/others & $05(7.6)$ \\
\hline \multirow[t]{4}{*}{3} & Type of aneurysm & \\
\hline & Secular & $57(87.7)$ \\
\hline & Fusiform & $02(3.1)$ \\
\hline & Others (specify) & $06(9.2)$ \\
\hline \multirow[t]{5}{*}{4} & Time duration to reach tertiary & care \\
\hline & $0-1$ day & $51(78.5)$ \\
\hline & $2-4$ days & $08(12.3)$ \\
\hline & $5-7$ days & 07 (10.76) \\
\hline & Mean \pm SD $2.74 \pm 1.98$ & \\
\hline
\end{tabular}

years. Aneurysmal SAH has a peak incidence of 40 to 60 years of age. ${ }^{11}$ According to Cowan et al., the mean age of patients with an aneurysm was 53.2 years, ${ }^{20}$ which is almost similar to that of our study findings. One of the largest studies, regarding cerebral aneurysm, reported that advanced age is the most significant risk factor associated with surgical outcome. ${ }^{21}$

Gender has a marked dominancy on the incidence of the cerebral aneurysm as they that found women have 1.6 times higher risk than men and prevalence of cerebral aneurysm in male and female was reported as 2:1.22 Female gender was dominating as $56.9 \%$ of the total study population were females in our study. Another study has also revealed that the female gender represents a significant risk factor as women outnumbered men among aSAH patients, especially along with increasing age strata. ${ }^{23}$

Headache in an acute and severe degree at the time of Ictus was the most common symptom registered as $95.4 \%$ of patients experienced a headache. Similar findings were reported by another study as the classic symptoms of aneurysmal rupture characterized by a sudden and severe headache which turn in the majority of cases at its utmost severity with no time and is often reported by patients as "the worst headache of my life", may last for a few hours or days. ${ }^{6,17}$ Both, the intensity and acute onset of severe headache are highly characteristic features of a ruptured cerebral aneurysm. Patients who already suffered from chronic headache before aneurysm rupture usually reported pain with an utmost difference in nature and intensity. ${ }^{24}$

Loss of consciousness is among the most common presenting symptoms of non-traumatic SAH. ${ }^{25}$ In our study, $44.6 \%$ of participants had experienced the loss of consciousness with the mean \pm SD duration of $4.82 \pm 6.962$. Other risk factors including seizure and COPD were almost equally distributed as $3.1 \%$ of patients.

A similar study conducted by Longstrn and colleagues supported our study findings as alcohol consumption, cigarette smoking, and hypertension have been studied as leading independent risk factors for $\mathrm{SAH} .{ }^{22}$ Our study results show that $21.5 \%$ of patients were having a history of alcohol intake with 1.43 \pm 3.321 of mean \pm SD duration. A long duration of heavy alcohol consumption is significantly associated with cerebral aneurysm rupture and the leading cause of transient increases in blood pressure. $^{26,27}$

Studies have found smoking as the most important established risk factors for aneurysmal SAH. ${ }^{6,12}$ Our study reported $29.5 \%$ of participants had a history of smoking with the mean \pm SD $3.20 \pm$ 6.162 duration. Cigarette smoke may lead to cerebral aneurysm genesis and rupture through several mechanisms as may influence each step in the cascade of events leading to aneurysm evolution, growth, and rupture recently reviewed. ${ }^{27}$ Patients harboring cerebral aneurysm should be strongly counseled to quit smoking and alcohol intact. The importance of this simple intervention cannot be overemphasized and counseling at the time of discharge and OPD visits.

Systemic hypertension has long been considered a primary risk factor of aneurysmal rupture. Hypertension was one of the most reported modifiable risk factors (64.6\%) found in our study and treatment adherence was $57.14 \%$ that shows a lack of treatment continuity among people suffering from hypertension. ${ }^{3,28}$ Most of the patients with a known history of hypertension are usually put on antihypertensive agents. So, they tend to have a normal range of blood pressure reading before an aneurysm diagnosed. ${ }^{21}$

Hence, blood pressure control is a pivotal practice that helps to control the risk of aneurysm rupture and medication adherence is needed to maintain as hypertension had been a positive effect on suffering to cerebral aneurysms.

Expanding population, ever-changing way of life, population aging, diabetes mellitus is the most common metabolic syndrome and a prime source of disability worldwide. In our study, $9.2 \%$ of patients had diabetes as a comorbid risk. ${ }^{29}$ Diabetes impacts the arterial wall and is a well-known trigger for cerebral infarction but that his connection with the development of $\mathrm{SAH}$, as the cause of ruptured aneurysms still remains unclear. ${ }^{29-31}$

Our study participants were from different age groups, backgrounds, and family types. The majority of the patients were residents of the rural area but the effect of geographical region on incidence and type of aneurysm rupture is indecisive at present. ${ }^{9}$ $78.5 \%$ of patients reached the tertiary care center within 24 hours of ictus.

Assessment of the patient's severity of condition immediately after a SAH is of the utmost importance and crucial to further management. $56.92 \%$ of patients had an aneurysm location at ACA/ ICA. Classification of severity of rupture should be done in a reliable way and with relevance to prognosis and outcome. Severe Hunt and Hess grades II was $58.7 \%$ generally consist of approximately $20-30 \%$ of those admitted to the hospital with aneurysmal SAH $36.9 \%$. The WFNS grading system uses the Glasgow Coma Scale and the presence of focal neurological deficits to grade the severity of $\mathrm{SAH}$. Where assessing patients with a proven aneurysmal $\mathrm{SAH}$, not only the clinical grading is important but also the amount of subarachnoid blood assessed by Fisher scale.

In an attempt to get a sense of the fate that befalls the patients of a ruptured cerebral aneurysm in our country, we studied the contributory factors and clinical profile of patients presenting to a high-volume center for aneurysmal surgery in North India. However, developing countries like India still is lagging in establishing such facilities for their vast population. 
Data were collected over 3 months and descriptive analysis was done. It is crucial to acknowledge risk factors related to cerebral aneurysms so that the information can be used to educate to avoid the modifiable risk factors.

\section{Conclusion}

Minimizing the risk of formation and rupture of cerebral aneurysm via modifiable risk factors identification and timely management, rather than surgical intervention is of great clinical and social value. Aneurysmal SAH is a life-threatening condition and the present study puts important information regarding symptoms and risk predictors of a ruptured cerebral aneurysm.

\section{Strength of Our Study}

The scope of studying sociodemographic and clinical profile is not limited to hospital services, and this information can also be utilized while making public health policies and implementation of cerebral aneurysm awareness programs.

\section{Analysis And Interpretation}

Collected data were analyzed by using descriptive analysis which is presented in the form of tables and figures.

\section{References}

1. King JT, Horowitz MB, Kassam AB, Yonas $H$, Roberts MS. The short form-12 and the measurement of health status in patients with cerebral aneurysms: performance, validity, and reliability. J Neurosurg 2005(3):489-493. DOI: 10.3171/jns.2005.102.3.0489.

2. Jill Novitzke RN. The basics of brain aneurysms: a guide for patients. J Vasc Interv Neurol 2008. 89-90.

3. Bederson JB, Connolly Jr ES, Hunt Batjer H, Dacey RG, Dion JE, Diringer $\mathrm{MN}$, et al. Guidelines for the management of aneurysmal subarachnoid hemorrhage: a statement for healthcare professionals from a special writing group of the stroke council American heart association. Stroke 2009;40(3):994-1025. DOI: 10.1161/ STROKEAHA.108.191395.

4. Rincon F, Rossenwasser RH, Dumont $A$. The epidemiology of admissions of nontraumatic subarachnoid hemorrhage in the United States. Neurosurgery 2013;3(2):217-222. DOI: 10.1227/01. neu.0000430290.93304.33.

5. Cohen-Gadol AA, Bohnstedt BN. Recognition and evaluation of nontraumatic subarachnoid hemorrhage and ruptured cerebral aneurysm. Am Fam Physician 2013;88:451-456.

6. Ju YE, Schwedt TJ. Abrupt-onset severe headaches. Semin Neurol 2010;30(02):192-200. DOI: 10.1055/s-0030-1249229.

7. Liebenberg WA, Worth R, Firth GB, Olney J, Norris JS. Aneurysmal subarachnoid haemorrhage: guidance in making the correct diagnosis. Postgrad Med J 2005;81(957):470-473. DOI: 10.1136/ pgmj.2004.023788.

8. Pierot LG, Gawlitza M, Soize S. Unruptured intracranial aneurysms: it is not a bomb. Rev Neurol 2017;173(9):530-531. DOI: 10.1016/j. neurol.2017.05.018.

9. Morita A, Kirino T, Hashi K, Aoki N, Fukuhara S, Hashimoto N, et al., UCAS Japan\#\#The natural course of unruptured cerebral aneurysms in a Japanese cohort. N Eng J Med 2012;366(26):2474-2482. DOI: 10.1056/NEJMoa1113260.

10. Juvela S, Korja M. Intracranial aneurysm parameters for predicting a future subarachnoid hemorrhage: a long-term follow-up study. Neurosurgery 2017;81(3):432-440. DOI: 10.1093/neuros/nyw049.

11. Broderick JP, Viscoli CM, Brott T, Kernan WN, Brass LM, Feldmann E, et al. Major risk factors for aneurysmal subarachnoid hemorrhage in the young are modifiable. Stroke 2003;34(6):1375-1381. DOI: 10.1161/01. STR.0000074572.91827.F4

12. Kleinloog RD, de Mul N, Verweij BH, Post JA, Rinkel GJE, Ruigrok YM. Risk factors for intracranial aneurysm rupture: a systematic review. Neurosurgery 2018;82(4):431-440. DOI: 10.1093/neuros/nyx238.

13. Rehman S, Sahle BW, Chandra RV, Dwyer M, Thrift AG, Callisaya M, et al. Sex differences in risk factors for aneurysmal subarachnoid haemorrhage. J Neurolog Sci 2019;406:116446. DOI: 10.1016/j. jns.2019.116446.

14. Feigin VL, Rinkel GJE, Lawes CMM, Algra A, Bennett DA, van Gijn J, et al. Risk factors for subarachnoid hemorrhage: an updated systematic review of epidemiological studies. Stroke 2005;36(12):2773-2780. DOI: 10.1161/01.STR.0000190838.02954.e8.

15. Almdal TS, Scharling $\mathrm{H}$, Jensen JS, Vestergaard $\mathrm{H}$. The independent effect of type 2 diabetes mellitus on ischemic heart disease, stroke, and death: a population-based study of 13,000 men and women with 20 years of follow-up. Arch Intern Med 2004;164(13):1422-1426. DOI: 10.1001/archinte.164.13.1422.

16. O'Donnell MJ, Xavier D, Liu L, Zhang H, Chin SL, Rao-Melacini P, et al. Risk factors for ischaemic and intracerebral haemorrhagic stroke in 22 countries (the INTERSTROKE study): a case-control study. Lancet 2010;376(9735):112-123. DOI: 10.1016/S0140-6736(10)60834-3.

17. Guimond JG, Chagnon P-M, Bojanowski MW. Clipping vs. Coiling in acute aneurysmal subarachnoid haemorrhage: should the patient's medical condition influence treatment modality. Neuro-Chirurgie 2012;58(2-3):115-124. DOI: 10.1016/j.neuchi.2012.02.012.

18. de Rooij NK, Linn FHH, van der Plas JA, Algra A, Rinkel GJE. Incidence of subarachnoid haemorrhage: a systematic review with emphasis on region, age, gender and time trends. J Neurol Neurosurg Psychiatry 2007;78(12):1365-1372. DOI: 10.1136/jnnp.2007.117655.

19. Aggarwal AS, Salunke $P$, Singh H, Kumar Gupta S, Chhabra R, Singla $\mathrm{N}$, et al. Vasospasm following aneurysmal subarachnoid hemorrhage: thrombocytopenia a marker. J Neurosci Rural Pract 2013;4(3):257-261. DOI: 10.4103/0976-3147.118762.

20. Cowan J, Dimick JB, Wainess RM, Upchurch Jr GR, Thompson BG. Outcomes after cerebral aneurysm clip occlusion in the United States: the need for evidence-based hospital referral. J Neurosurg 2004;99(6):947-952. DOI: 10.3171/jns.2003.99.6.0947.

21. Wiebers DO, Whisnant JP, Huston 3rd J, Meissner I, Brown Jr RD, Piepgras DG, et al. Unruptured intracranial aneurysms: natural history, clinical outcome, and risks of surgical and endovascular treatment. Lancet 2003;362(9378):103-110. DOI: 10.1016/S0140-6736(03) 13860-3.

22. Eden SV, Meurer WJ, Sánchez BN, Lisabeth LD, Smith MA, Brown DL. Gender and ethnic differences in subarachnoid hemorrhage. Neurology 2008;71(10):731-735. DOI: 10.1212/01. wnl.0000319690.82357.

23. De Marchis GM, Schaad C, Fung C, Beck J, Gralla J, Takala J. Genderrelated differences in aneurysmal subarachnoid hemorrhage: a hospital based study. Clin Neurol Neurosurg 2017;157:82-87. DOI: 10.1016/j.clineuro.2017.04.009.

24. Cebral JR, Mut F, Weir J, Putman CM. Association of hemodynamic characteristics and cerebral aneurysm rupture. AJNR Am J Neuroradiol 2011;32(2):264-270. DOI: 10.3174/ajnr.A2274.

25. Suwatcharangkoon SM, Meyers E, Falo C, Schmidt JM, Agarwal S, Claassen J, et al. Loss of consciousness at onset of subarachnoid hemorrhage as an important marker of early brain injury. JAMA Neurol 2016;73(1):28-35. DOI: 10.1001/jamaneurol.2015.3188.

26. Can AC, Castro VM, Ozdemir YH, Dagen S, Dligach D, Finan S, et al. Alcohol consumption and aneurysmal subarachnoid hemorrhage. Transl Stroke Res 2018;9(1):13-19. DOI: 10.1007/s12975-0170557-z.

27. Chalouhi NA, Chalouhi N, Ali MS, Starke RM, Jabbour PM, Tjoumakaris $\mathrm{SI}$, et al. Cigarette smoke and inflammation: role in cerebral aneurysm formation and rupture. Mediators Inflamm 2012;2012:271582. DOI: 10.1155/2012/271582. 
28. Nuki YT, Tsou T-L, Kurihara C, Kanematsu M, Kanematsu $Y$, Hashimoto T. Elastase-induced intracranial aneurysms in hypertensive mice. Hypertension 2009;54(6):1337-1344. DOI: 10.1161/ HYPERTENSIONAHA.109.138297.

29. Shaw JE, Sicree RA, Zimmet PZ. Global estimates of the prevalence of diabetes for 2010 and 2030. Diabetes Res Clin Pract 2010;87(1):4-14. DOI: 10.1016/j.diabres.2009.10.007.
30. Murray CJL, Vos T, Lozano R, Naghavi M, Flaxman AD, Michaud C, et al. Disability-adjusted life years (DALYs) for 291 diseases and injuries in 21 regions, 1990-2010. Lancet 2012;380(9859):2197-2223. DOI: 10.1016/S0140-6736(12)61689-4.

31. American Diabetes Association. Diagnosis and classification of diabetes mellitus. Diabetes Care 2010;33(Suppl 1):S62-S69. DOI: 10.2337/dc11-S062. 